\title{
Construyendo caminos y fundamentos posibles en búsqueda de una enseñanza de las ciencias naturales en contextos de interculturalidad
}

\section{In search of ways to teach natural sciences in intercultural contexts: building possible paths and foundations}

\author{
iD Martín Pérgola' \\ iD Geraldine Chadwick ${ }^{2}$ \\ Leonor Bonan ${ }^{1}$

\begin{abstract}
'Universidad de Buenos Aires (UBA), Centro de Formación e Investigación en Enseñanza de las Ciencias (CEFIEC), Facultad de Ciencias Exactas y Naturales, Buenos Aires, Argentina.

${ }^{2}$ Universidad de Buenos Aires (UBA), CONICET, Instituto de Investigaciones en Ciencias de la Educación (IICE), Buenos Aires, Argentina. Autora correspondiente: geralchad@ccpems.exactas.uba.ar
\end{abstract}

Resumen: Este trabajo presenta una reflexión metacientífica sobre la implementación de enfoques interculturales con pueblos aborígenes, en particular del noroeste argentino. Para ello, se plantean tres bases o fundamentos desde la epistemología, la sociología y la enseñanza de las Ciencias Naturales, desde los cuales analizar y sustentar enfoques interculturales en la enseñanza de las ciencias. El objetivo principal es sentar una base teórica para valorizar a partir de una reflexión metacientífica, la importancia y la necesidad de incorporar un enfoque de educación intercultural para el conjunto de la población, que aporte a favorecer el aprendizaje de competencias y contenidos científicos.

Palabras clave: Educación intercultural; Didáctica de las ciencias naturales; Educación escolar indígena.

\begin{abstract}
In this paper, we present a meta-scientific reflection on the implementation of intercultural approaches with aboriginal peoples, in particular from the Argentine Northwest. To this end, we propose three bases or foundations that take into account epistemology, sociology, and the teaching of natural sciences, from which to analyze and in which to ground intercultural approaches in the teaching of sciences. Based on a meta-scientific reflection, the main goal is to establish a theoretical basis to value the importance and the need to incorporate an intercultural education approach for the population as a whole, which contributes to favor the learning of scientific competencies and content.

Keywords: Intercultural education; Natural sciences didactics; Indigenous school education.
\end{abstract}

Recebido em: 24/08/2020

Aprovado em: 31/05/2021 


\section{Introducción}

Las prácticas educativas, como toda relación social, implican la necesidad que exista una comunicación efectiva entre los actores, en el caso particular del espacio del aula entre estudiantes y docentes. Esta relación requiere que se establezcan acuerdos de significados que le den sentido a la actividad, por lo cual es una práctica intermediada por sistemas de signos que permiten la comunicación entre los sujetos. Este hecho, que parece evidente para toda relación social donde se ponga en juego el lenguaje, muchas veces no se hace consciente por aquellos que están a cargo de las actividades educativas, lo cual hace que pasen desapercibidos los desacuerdos entre estudiantes y docentes. EI desacuerdo de significados produce un desencuentro que se constituirá seguramente en un obstáculo en la comunicación entre docentes y estudiantes, y consecuentemente en un obstáculo de enseñanza y aprendizaje. En el ámbito educativo, es común que los docentes presenten información a los estudiantes con distintos formatos de lenguaje como el gráfico, el verbal, el matemático, el químico, etc. Inclusive en el caso en que estudiantes y docentes hablen el mismo idioma, los significados de los lenguajes apelados por los docentes para comunicar modelos científicos, son desconocidos muchas por los estudiantes, convirtiéndose en una novedad para ellos. Si el profesor usa términos cuyos significados refieren al lenguaje de la ciencia erudita, mientras que el estudiante utiliza un lenguaje basado en su cotidianidad o su cosmovisión, sin que se haga explícita y se establezca una relación entre los mismos, habrá una desconexión y no se estará logrando la comunicación esperada.

En lo que atañe a la Educación Intercultural Bilingüe (EIB), este hecho es muy relevante, pues si a los obstáculos generados a partir del uso de lenguaje científico, se agrega el desconocimiento cultural originario - en algunos casos una desvalorización de esta cultura y sus conocimientos - es una garantía de desencuentro por partida doble. Partiendo de esta base, cualquier propuesta educativa que pretenda abordar contenidos desde el enfoque de la interculturalidad, tendrá que poner particular atención en considerar esta construcción de significados dentro del aula escolar, no sólo desde el punto de vista de los modelos de Ciencias Naturales que se pretendan enseñar, sino también desde la cultura de los distintos actores involucrados en las prácticas. Asimismo, es de vital relevancia poder tender puentes comunicativos entre saberes vernáculos y el conocimiento científico desde un lugar de valoración (CHADWICK; BONAN, 2018). Teniendo en cuenta trabajos de investigación previos en lo que a la Didáctica de las Ciencias Naturales en torno a la EIB respecta (BONAN 2017; CHADWICK, 2019), el objetivo principal de este artículo de reflexión es presentar tres fuentes de fundamentación del enfoque de una Didáctica de las Ciencias Naturales posible en contextos de diversidad cultural, de manera tal de vislumbrar caminos factibles de prácticas de enseñanza de las Ciencias Naturales decoloniales.

\section{Presentación de los fundamentos como núcleo constitutivo}

Desde un análisis que tenga al lenguaje como eje estructurante, se proponen tres fundamentos que pueden ser utilizados en la enseñanza de las Ciencias Naturales en contextos de EIB. 
1. Fundamento desde lo epistemológico. La enseñanza de las Ciencias Naturales es considerada en la actualidad una actividad específica con un desarrollo particular y autónomo dentro del campo de las Ciencias Naturales y de las Ciencias de la Educación (ADÚRIZ-BRAVO; IZQUIERDO, 2002). Las formas de construcción de conocimiento son independientes de la cultura, pues es una condición netamente humana ya que no hay racialización en las maneras de construir el conocimiento (LAM; FRISANCHO; VILLALBA, 2020). Sin embargo, la escuela siempre fue una institución privilegiada para abordar los procesos de definición y transmisión cultural (NOVARO, 2011), donde la ciencia a enseñar, occidental, ocupa lugares privilegiados. Los rasgos culturales de estudiantes y docentes deben ser considerados, dentro de una perspectiva en búsqueda de una educación científica culturalmente diversa, como factores a tener en cuenta para planificar programas educativos y actividades escolares específicas para cada población a la que se destinan.

2. Fundamento desde la sociología de la educación. Considerar la Educación intercultural al interior de las clases de Ciencias Naturales contribuiría a visibilizar y valorizar las culturas de los pueblos originarios, pueblos inmigrantes, minorías étnicas, etc. Esto aportaría a que estas poblaciones encuentren un lugar propicio en las instituciones educativas para su desarrollo subjetivo y el de su comunidad, lo cual favorecería la escolarización y colaboraría a disminuir la deserción escolar.

3. Fundamento desde la enseñanza de las Ciencias Naturales. La enseñanza de modelos científicos requiere considerar las representaciones mentales de los estudiantes, sus concepciones y sus modelos explicativos sobre el mundo. Sus formas de explicar la naturaleza forman sistemas coherentes que les permiten operar sobre el mundo, pero que están relacionadas con el sentido común, como también con representaciones sociales y no con los modelos científicos eruditos. Es esperable entonces, que las concepciones y modelos explicativos de los estudiantes varíen de acuerdo a sus distintas culturas de pertenencia. Encarar las actividades educativas considerando lo que piensan los estudiantes es indispensable para lograr mejores aprendizajes.

A continuación se desarrollarán cada uno de estos fundamentos de forma tal de poder caracterizarlos en base al objetivo trazado.

\section{Fundamentación epistemológica}

La educación científica implica prácticas y escenarios específicos con características propias que constituyen un contexto particular de la actividad científica, el contexto de educación. Siguiendo a Echeverría (1998), si se persigue el objetivo de comprender un enunciado científico es necesario previamente aprender un sistema de complejos conocimientos, prácticos y teóricos, sin los cuales no existe manera de revelar y justificar como así tampoco de emplear el conocimiento científico. Este mismo autor afirma que la enseñanza de la ciencia es socialmente normada y también posee técnicas propias de valoración, justificación, representación y aplicación de las teorías científicas las cuales no tienen por qué ser iguales a las utilizadas en otros ámbitos de la actividad científica (ECHEVERRÍA, 1998).

El objetivo de la actividad científica escolar consiste en que los estudiantes construyan representaciones mentales que permitan generar modelos explicativos para 
intervenir en la realidad, basados en los modelos científicos escolares. La construcción de conocimientos mediante actividades de enseñanza son procesos socioculturales que dependen de los actores que participan en particular de sus culturas, su contexto social y su lenguaje.

Entonces, es relevante aclarar que para planificar actividades y diseñar materiales de enseñanza con estas características es necesario considerar el contexto sociocultural, las particularidades de cada población, así como la subjetividad de los estudiantes.

En este sentido, la educación intercultural se plantea recuperar y ubicar en un sitio de valoración los conocimientos tradicionales ancestrales estableciendo relaciones simétricas con los saberes de la ciencia occidental (CHADWICK, 2019). Según esta misma autora, de esta manera, la interculturalidad se dirige a la edificación epistémica de una nueva condición social de saber, percibida como fracción de un proyecto político en respuesta a legados coloniales aún presentes en Nuestra América - término acuñado por Martí (1977) y Cullen (2016), de forma tal de incorporar a aquellos pueblos que no hablan una lengua proveniente del latín, ya que el término América Latina o Latinoamérica dejaría afuera a estas personas. Por otra parte, Walsh (2005) explica cómo se genera una pérdida crítica y transformadora en el ámbito estatal adjudicando un sentido discernimiento multi o pluri culturalista, comprendido como la inclusión de la diversidad étnica dentro de estructuras sociales, políticas y de conocimiento existentes sin modificar la presente hegemonía dominante, siendo la EIB un ejemplo de ello. Se puede afirmar esto último ya que la EIB (en su conjunto) se plantea como una modificación transversal a los enfoques y programas de enseñanza de todo el país dejando intactas relaciones de poder, de organización de espacios, tiempos, contenidos y prácticas propias de la escuela moderna (THISTED, 2016).

Desde esta perspectiva intercultural es posible hacer énfasis en la necesidad de enfoques de manera tal de que en las aulas no sean atravesadas por cuestiones culturales meramente descriptivas, reduciendo los procesos de producción de saberes ancestrales (CHADWICK, 2019). Asimismo, esta misma autora afirma que la educación intercultural tiene que ser para todos y no para unos pocos o sectores reducidos, como ocurre en la realidad cotidiana de la EIB, la cual solo atiende a poblaciones aborígenes en particular, siendo la educación intercultural una forma de cimentar nuestra identidad contextual sudamericana.

Hecha esta distinción, se convierte en fundamental el caso particular de la educación intercultural específicamente bilingüe para tomar los problemas educativos emergentes que la permean.

\section{El problema de la lengua como primer obstáculo}

En la Argentina se hablan en la actualidad entre 12 y 14 lenguas vernáculas además del español (ARGENTINA, 2012) mientras que en el momento de la llegada de los españoles se estima que se hablaban no menos de 35 (CENSABELLA, 2005; MESSINEO; CÚNEO, 1998). Dentro de la población podemos encontrar individuos que utilizan habitualmente dos lenguas (bilingües) en distintos ámbitos y aquellos que utilizan varias lenguas (multilingües). Según el último censo del año 2010, cerca del $2.4 \%$ de la población total de la Argentina se autoreconocían como indígenas o descendientes de indígenas, mientras que el 38,74 \% de la población aborigen total 
pertenece a la franja de 0-19 años, por lo cual están en situación de estar transcurriendo la educación obligatoria (ARGENTINA, 2012).

Censabella (2005) distingue zonas donde existe un contacto entre lenguas, como aquellas en donde hay un porcentaje significativo de habitantes que hablan dos o más lenguas. Entre ellas distingue zonas de frontera de la Argentina con países limítrofes como Paraguay, Brasil y Bolivia, este es el caso particular de las provincias de Misiones, Formosa y Jujuy; zonas rurales con población indígena como ocurre en las provincias de Chaco y Formosa, y las grandes ciudades tales como Ciudad Autónoma de Buenos Aires, Rosario, Córdoba y Santa Fe, que reciben migrantes de distintas partes de Argentina y de países limítrofes.

En las zonas de las grandes ciudades donde se concentra el mayor porcentaje de la población argentina, no sólo hay pobladores que hablan lenguas indígenas sino que además los inmigrantes de países europeos y asiáticos mantienen sus lenguas vernáculas (MESSINEO; CÚNEO, 1998). Si bien en este caso el uso de la lengua se da en ámbitos familiares o intracomunitarios, se puede hablar de personas bilingües.

A partir de lo anterior se puede proponer, en cuanto a la cantidad de lenguas que se hablan en la Argentina, que se trata de un país multilingüe aunque el porcentaje de población que habla dos o más idiomas en sus ámbitos cotidianos es minoritario. Este hecho es suficiente para justificar un enfoque multilingüe de la situación, que debería poner mayor énfasis en generar espacios educativos institucionales donde se hablen los idiomas de los estudiantes que concurren al mismo y, en aquellos casos donde la población bilingüe no fuera significativa, cuanto menos atender las necesidad de los hablantes en lenguas que no sean la lengua oficial.

El lenguaje cumple un rol fundamental entre el desarrollo y el aprendizaje. No puede ser reducido a una herramienta de comunicación sino que es lo que permite estructurar el pensamiento mediante la internalización de prácticas sociales (VYGOTSKY, 1978). Según Ivic (1994), el lenguaje como instrumento de las relaciones sociales se convierte en herramienta de la organización psíquica interna del niño ya que concibe la aparición del lenguaje privado, del lenguaje interior, del pensamiento verbal, etc. El papel de los adultos es fundamental en el proceso donde el niño se apropia de una parte de la cultura de la sociedad a través de la lengua. En la mayoría de los casos, el proceso de aprendizaje de la lengua vernácula se da al interior de la familia y de la comunidad, mientras que en la educación formal e institucionalizada se conforma el de lengua oficial.

En lo que respecta al enfoque intercultural y siguiendo a Cortina y Earl (2020), uno de los obstáculos en cuanto a la efectiva implementación de la EIB que se ha señalado en muchos contextos locales, es la falta de un número adecuado y de formación de hablantes de lenguas indígenas locales que estén preparados para servir como maestros o profesores en programas interculturales y/o bilingües. Estos mismos autores afirman que también se debe considerar que en las últimas dos décadas, el número de programas de educación superior que se enfocan en el desarrollo de docentes y profesionales indígenas desde una perspectiva intercultural, ha crecido en muchos países de Nuestra América, como así también en otras regiones del mundo. Sin embargo, todavía existe una falta de atención y puesta en escena de las voces y experiencia de maestros y profesores indígenas locales en lo que respecta a la práctica educativa, las metodologías y la producción de conocimiento (CORTINA; EARL, 2020). 
Por otra parte, existe lo que Olivares y Pena (2015) denominan mediación intercultural, como un tipo de traducción/interpretación realizada por los mediadores interculturales en entornos de servicio público. El objetivo de la mediación intercultural es la autonomía de los grupos minoritarios con el fin de crear un marco común de convivencia entre personas de otras culturas/lenguas y el personal que trabaja en lugares públicos, como los campos de la salud, el derecho, la educación y la administración, cerrando así la brecha entre los hablantes nativos y los que no hablan ese mismo idioma. Este tipo de traductor/intérprete no solo está traduciendo o interpretando el discurso particular de un individuo a otro idioma, sino que incluye aspectos claves de la comunicación cultural y no verbal. En el contexto de la EIB que nos concierne, este rol podría asignarse a los Profesores originarios, ya que son los actores puente entre los estudiantes aborígenes y los docentes mestizos de las instituciones educativas que solo hablan español, interpretando no solo el acto lingüístico sino adaptándolo a la situación, considerando los rasgos culturales y contextuales involucrados.

Es importante destacar que países como México en donde se promulgó la Ley General de Derechos Lingüísticos de los Pueblos Indígenas tiene al menos cierto nivel de protección contra la discriminación lingüística en la esfera pública, particularmente en la educación, pero también en el ámbito legal y administrativo (TANNER, 2012). Este mismo autor afirma que desde la perspectiva del formador de docentes, se requiere que las escuelas comiencen un programa especializado en educación indígena, pretendiendo que los maestros y profesores hablen y escriban el idioma de su comunidad, obligándolos a tener un conocimiento cultural de su comunidad, enfatizando un mayor enfoque sobre la cultura indígena en todas las aulas, tanto públicas como privadas.

\section{Ciencia occidental vs. conocimientos ancestrales: un juicio binario improductivo en el contexto de la EIB Argentina}

El debate sobre los contenidos a enseñar y el enfoque educativo no debe reducirse a un debate que enfrente las concepciones y modelos explicativos propios de las culturas originarias y los modelos de ciencia escolar derivados de la ciencia occidental. Según Horsthemke y Yore (2014), las resoluciones de conflicto que siguieron lógicas binarias de bueno o malo, ciencia o pseudociencia, conocimiento y sabiduría indígena o ciencia moderna occidental, no lograron reflejar adecuadamente las realidades del mundo en las clases de ciencia en poblaciones de diversidad cultural.

El conocimiento y sabiduría indígena - indigenous knowledge and wisdom (IKW) según Horsthemke y Yore (2014) -, es diferente a la ciencia moderna occidental, pero cada uno tiene un valor subjetivo de los sistemas de conocimiento interpersonales de las comunidades. Por otra parte, Molina y Mojica (2013) en sus estudios acerca de las concepciones de los profesores de ciencias sobre el fenómeno de la diversidad cultural y sus implicancias con la enseñanza en contexto, definen diferentes posturas docentes en torno cómo deben relacionarse los conocimientos científicos escolares (CCE) y los conocimientos tradicionales-ancestrales (CET) en las clases de ciencias. Mediante ello realizan aportes a la conceptualización de los procesos de enseñanza realizados en contextos de diversidad cultural. Desde otra perspectiva, Chadwick y Bonan (2018) estudian cómo encontrar vínculos o puentes conceptuales entre los conocimientos 
científicos y los conocimientos vernáculos en clases de Ciencias Naturales a través de temáticas en común acerca del cielo.

Teniendo en cuenta gran parte de los resultados de las investigaciones anteriormente mencionadas en el contexto de la EIB Argentina (BONAN, 2017a; CHADWICK, 2019; CHADWICK; BONAN, 2018), se puede afirmar que no tiene ningún sentido el intento de desplazar o reemplazar los saberes indígenas por las teorías y modelos de la ciencia moderna occidental. La enseñanza de modelos científicos escolares tiene como fin que los estudiantes los utilicen para explicar y operar sobre el mundo. Es decir, el aprendizaje de los modelos científicos por parte de los sujetos no se limita a la incorporación de contenidos científicos canónicos, sino a una reestructuración de su sistema cognitivo que permita generar formas distintas de explicar y operar en el entorno.

Otros autores tales como Molina et al. (2009) caracterizan algunas reflexiones y avances sobre la diversidad cultural e implicaciones en la enseñanza de las ciencias, intentando comprender la homogeneización en la educación del territorio de Nuestra América. Estos mismos autores entienden en que la diversidad cultural implica aspectos políticos, ontológicos, epistémicos y axiológicos muy difíciles de separar, por lo cual es importante tener en cuenta que en una Educación en ciencias en contextos multiculturales existe un abanico de cogniciones, concepciones y cosmovisiones del sujeto de aprendizaje. De esta forma, se suplementaria, un marco de compresión sobre un otro, su pensamiento y la valoración positiva referente a las circunstancias diversas y heterogéneas de la cultura de Nuestra América.

En lo que respecta a la búsqueda de justificaciones para una educación científica multicultural, autores como El-Hani y Sepúlveda (2006) remarcan que el debate sigue abierto. Algunos autores académicos se ocupan de promover una educación científica sensible al contexto cultural, con el fin de no violentar las cosmovisiones y creencias originarias no compartidas por la ciencia a enseñar. Mientras que otros autores, que critican la postura previa, consideran que con la defensa de una enseñanza de las ciencias sensible a las cosmovisiones y creencias culturales estudiantiles, se estaría violentando el conocimiento científico a ser enseñando ya que al ser universal, no podría ser entendido en términos multiculturales (EL-HANI; SEPÚLVEDA, 2006; MOLINA et al., 2009).

Siguiendo a estos mismos autores, este debate ha sido promovido por posiciones morales y políticas, como así también a través de discusiones epistemológicas acerca de los estatutos de la ciencia moderna y sus relaciones con otras formas de conocimiento, caracterizándose de forma breve por los siguientes posicionamientos:

- Los universalistas: sostienen que la ciencia posee un carácter universal sostenido por su cuerpo de conocimientos y actividades, es por eso que no puede ser enseñada en términos multiculturales. Esta mirada encierra el hecho de que la ciencia moderna occidental posee un poder epistémico superior a otras formas de conocimiento.

- Los multiculturalistas: argumentan que el universalismo y su política de exclusión son incorrectos desde los puntos de vista políticos, morales y epistemológicos, proponiendo la inclusión de los saberes ecológicos tradicionales en los currículos escolares de la ciencia a enseñar.

- Los pluralistas epistemológicos: sostienen que el conocimiento científico es 
una manera específica de conocimiento pero no aceptan la distinción de otras formas de conocimiento, sobrevalorando así, el conocimiento científico.

En lo que respecta a esta última postura, autores como Cobern y Loving (2001) sostienen que no se trata de dar más valor a la ciencia moderna occidental por encima de saberes de otros orígenes, sino de pensar en la utilidad de la demarcación de estas otras formas de conocer el mundo. Desde esta visión, se hace referencia a los conocimientos ecológicos, la literatura, el arte y la religión, no refiriéndose solamente a la definición tradicional de conocimiento científico sino al acentuado cientificismo vigente hoy en día en las sociedades (MOLINA et al., 2009). Por otra parte, El-Hani y Mortimer (2007) respaldan que un objetivo adecuado de enseñanza de las ciencias es la comprensión de teorías, modelos y conceptos científicos por parte de los estudiantes, sosteniendo que si la enseñanza de las ciencias adopta como meta el cambio de creencias, corre el riesgo de degenerar directamente una ciencia proselitista y adoctrinante. La decisión de creer o no en ideas científicas depende de los estudiantes, pero ellos necesariamente tienen derecho a comprender esas ideas, si quieren tener éxito en la ciencia escolar como aprendices (EL-HANI; MORTIMER, 2007). Siguiendo a estos mismos autores, es más probable que si un profesor o maestro estimula a sus alumnos a tener éxito en este sentido, les dé un espacio significativo para que sus voces se manifiesten en las interacciones discursivas, en las acciones en el aula de ciencias, sin perder de vista el objetivo de la comprensión en la ciencia escolar.

Desde otras perspectivas interculturales otros autores (GROSFOGUEL, 2006; HARDING, 1994; RAJ, 2007) tienen aportes adicionales a este debate, ya que hacen referencia a que ningún ser humano escapa a la clase, lo sexual, el género, lo espiritual, lo lingüístico, lo geográfico y las jerarquías raciales de las categorías: mundo moderno-colonial capitalista-patriarcal. Es decir, que nuestros conocimientos siempre están situados. Esta última afirmación refiere a que todos los conocimientos están ubicados epistémicamente en el lado subalterno o dominante de las relaciones de poder, siendo clave la geo y cuerpo-política del conocimiento derrumbando así el mito de la objetividad y neutralidad de la ciencia occidental (GROSFOGUEL, 2006). Este mismo autor afirma que se interpreta por conocimiento subalterno a aquellos que se encuentran en la intersección de lo tradicional y lo moderno, entendiéndose como formas híbridas, transculturales y no en el simple sentido de mestizaje sino en contra del sistema. Asimismo, son modalidades de resistencia mediante las cuales las formas del conocimiento dominante se resignifican y transforman dando lugar al punto de vista de la racionalidad no eurocéntrica.

Es importante destacar también que según Chadwick (2019), a través de los años de escolarización, la educación formal aporta a la elaboración o evolución de una polifasia de una cosmovisión en la que se asienta la ciencia occidental y otra en la que radican los conocimientos ancestrales. Esta polifasia brinda las raíces sobre las cuales los esquemas cognitivos son edificados durante el proceso de aprendizaje (CHADWICK, 2019). Esta misma autora afirma que desde una perspectiva epistemológica que ignora otros saberes o estima que el único conocimiento legítimo es la ciencia occidental, la cual no puede enseñarse a riesgo de aislar a los estudiantes de su inserción social, la ciencia tradicional se posiciona como criterio único de postulación de verdad y creación de conocimiento. En este escenario, la interculturalidad se propone colocar en un lugar de valoración y recuperar los conocimientos ancestrales interrelacionándolos 
con los saberes de la ciencia erudita de forma tal de construir vínculos o puentes comunicativos entre ellos. Por lo tanto, la interculturalidad se dirige a la cimentación epistémica de una nueva circunstancia social del saber, concebida como parte de un proyecto político en respuesta a los legados coloniales aún presentes en Nuestra América.

\section{Fundamentación desde la sociología de la educación}

El reconocimiento de la cultura de los pueblos, el campo de saberes aborígenes, los valores de estudiantes y trabajadores de la educación involucrados en las prácticas educativas, implica una valorización de la comunidad, lo cual debería influir en una mejor consideración subjetiva de las actividades educativas y posiblemente en un aumento de la autoestima de los estudiantes como participantes centrales de dichas actividades. La presencia del estudiante y su participación, desde sus conocimientos y valores, es trascendente y relevante para la educación. El no reconocimiento cultural del estudiante, hace que su presencia sea silenciada dentro del aula y la planificación escolar, anulándolo como sujeto.

Algunas experiencias en Nuestra América como la de Bolivia señalan que la implementación de la Educación Intercultural resultó positiva en cuanto al desarrollo afectivo y de la autoestima de estudiantes aborígenes. El uso de la lengua aborigen originaria permite que los estudiantes se comuniquen mejor entre ellos y con sus docentes, además de ser más espontáneos (NUCINKIS, 2006), como así también permite plasmar mejor sus ideas durante las clases escolares. La comunicación de los estudiantes entre ellos es un factor determinante para el trabajo grupal que favorece el debate, la confrontación de representaciones idiosincrásicas, el trabajo colaborativo, y en definitiva la construcción de conocimiento entre pares (PERKINS, 2016).

Retomando lo planteado en la sección previa, la planificación de las actividades de enseñanza, requiere atender la especificidad que implica el público destinatario de estas actividades, no considerarlas será un probable origen de obstáculos de aprendizaje.

\section{El reconocimiento del otro en las actividades de enseñanza}

Para el caso de los pueblos indígenas, su reconocimiento como actores educativos implica que sean parte del proceso de armado de los diseños curriculares y de las decisiones que implican su puesta en práctica concreta.

En países como Bolivia donde el $62 \%$ de sus habitantes se consideran indígenas, la recomposición del movimiento indígena permitió que distintos pueblos hayan podido reconstruir parte de su identidad. En el marco de la refundación del Estado en Bolivia como plurinacional, en el año 2010 se dictó la Ley nº 070 Avelino SiñaniElizardo Pérez (BOLIVIA, 2010), la cual hace hincapié en transmitir una educación pública, universal, democrática, participativa, comunitaria, descolonizadora y de calidad y, a su vez, aclara la vital importancia de que dicha educación sea: intracultural, intercultural y plurilingüe en todo el sistema educativo.

El proceso de la interculturalidad en la Argentina tuvo características muy distintas, pues se dio en el marco de un estado que solo reconoció parcialmente a los pueblos aborígenes e incorporó la educación intercultural de forma muy limitada, 
localizada y descriptiva, respondiendo al modelo neoliberal educativo (HIRSCH; SERRUDO, 2010a).

Tal como afirma Walsh (2010), lo intercultural en la EIB se ha construido mediante dos factores, el primero en términos lingüísticos, y el segundo recae en el reconocimiento, respeto y la tolerancia del otro culturalmente diferente sin generar un cambio mayor o transformación. Esta problemática también se refleja en ámbitos como la elaboración de textos escolares, formación de profesores y los currículos escolares (CHADWICK, 2019). Walsh (2010) hace hincapié en que la interculturalidad en la formación docente se limita a la letra escrita y en las aulas institucionales su aplicación es netamente marginal. Si bien se reconoce que la EIB es para todos, su propuesta pedagógica recae en el entendimiento de lo intercultural centrado en el indígena, ya que solo se dispone de la modalidad EIB en contextos escolares cuya población estudiantil sea mayoritariamente originaria. Superficialmente se incorporan asignaturas relacionadas a la diversidad cultural y lingüística, dejando de lado la relación de conocimientos y saberes ancestrales dado que se reconoce que el conocimiento y la ciencia no son únicos y singulares.

Los líderes indígenas que opinaron sobre este aspecto manifiestan que el acceso que tuvieron a espacios de toma de decisiones y de gestión del estado resultaron parcialmente positivos para la implementación de la EIB en Argentina. Sin embargo, mencionaron que esta inclusión resultaba contradictoria, confusa en algunos casos y reconocen que fue, en la gran mayoría de los casos, una conquista producto de la lucha de los propios pueblos indígenas contra el estado (LOPEZ; ROJAS, 2006).

En el caso argentino, las experiencias fueron diferentes en cada una de las provincias. En algunas, como Formosa, las comunidades indígenas participaron en mayor medida de la implementación de la EIB, mientras que en Salta o Chaco la participación fue más marginal.

La participación de los propios actores educativos, tanto los estudiantes, como miembros de las comunidades, como los trabajadores docentes del sector, debería ser - en todo diseño educativo pero en la EIB en particular - un factor determinante en el armado de los programas educativos y el diseño e implementación de las prácticas de este tipo de programas.

\section{Enfoques tradicionales como obstáculos en el aprendizaje y en la escolaridad}

A lo largo de la historia de la didáctica escolar se ha demostrado cómo los enfoques educativos tradicionales, en escenarios de diversidad cultural, actúan de manera perjudicial para los estudiantes (HIRSCH; SERRUDO, 2010a). Este no es un fenómeno exclusivo de las poblaciones originarias que viven en el territorio argentino, sino que también ocurre con otros pueblos de Nuestra América. En las investigaciones presentadas en Lopez y Rojas (2006) se pueden ver los casos de Perú, Bolivia y Ecuador, donde la educación tradicional muestra índices de deserción y desgranamiento más elevados para los casos de los pueblos indígenas en comparación con las poblaciones criollas ${ }^{1}$.

Como muestran estas y otras investigaciones, considerar un enfoque intercultural ataca fundamentalmente la deserción, el desgranamiento y el abandono escolar,

'Se le llama criollos a aquellas personas que descienden de europeos y han nacido en un país hispanoamericano. 
favoreciendo la presencia de los estudiantes en los distintos proyectos educativos, generando un aumento de la autoestima y valorizando su rol central en la actividad educativa. Un estudiante que es valorizado como actor central de la actividad educativa, cuya enseñanza no sólo depende de los docentes y de su institución escolar, sino está comprometido de manera consciente en su propio aprendizaje, se sentirá más protagonista en ese escenario educativo y esto repercutirá positivamente en su autoestima, lo cual favorecerá la motivación para el aprendizaje (CHADWICK, 2019; VOSNIADOU et al., 2001).

La consideración del estudiante indígena desde una perspectiva intercultural, permite que se comprometa con la actividad educativa, que la recontextualice y la resignifique en consonancia con su entorno cultural específico, y que tome una posición en su propio aprendizaje.

Por último, el enfoque intercultural valoriza el rol del docente, que debe hacer aportes específicos y precisos en este proceso de incorporación transversal de contenidos interculturales. La especificidad de la tarea docente refuerza su rol como profesional de la educación que debe intervenir en un contexto único, rechazando la noción tradicional del docente como un simple reproductor de técnicas educativas diseñadas a priori.

De ahí que se desprende una propuesta o una conclusión importante: las modificaciones curriculares que apunten a introducir enfoques como el de enseñanza intercultural bilingüe tienen que ser abordadas desde las etapas de formación de los docentes y acompañadas por capacitación docente sobre interculturalidad; no alcanza con una implementación superficial, sino que los docentes tienen que ser preparados para trabajar con las propuestas interculturales.

\section{El desarrollo capitalista en Argentina y la opresión sobre los pueblos aborígenes}

\section{La acumulación originaria y el confinamiento de los pueblos}

En Argentina, al igual que en la mayoría de los países americanos, el desarrollo del sistema capitalista fue tardío en relación con las potencias europeas y los Estados Unidos. Esto generó la formación de una burguesía nacional débil, sometida a las potencias imperialistas. En particular, en el Noroeste argentino, la incorporación del Gran Chaco al desarrollo capitalista, actuó como un factor de proletarización forzosa de amplios sectores de la población aborigen, de características nómades y seminómades, que pasaron a realizar un trabajo asalariado en condiciones de suma precariedad para las empresas de explotación de quebracho, las tabacaleras, las empresas de ferrocarriles, los ingenios azucareros, etc. que se instalaron en esa zona (CARRERA, 1984, 1988).

Este proceso se caracterizó por una acumulación por desposesión, donde la explotación no se remitió solamente a la expropiación del trabajo de los y las trabajadoras, sino que también hubo una acumulación de capital basada en la adquisición de bienes o recursos privados que se encontraban al momento relativamente fuera del mercado (HARVEY, 2004; SEOANE; TADDEI; ALGRANATI, 2010). El concepto de acumulación por desposesión, acuñado por el antropólogo y geógrafo David Harvey (HARVEY, 2004), está relacionado con el de acumulación originaria 
presentado por Karl Marx en los capítulos XXIV y XXV del primer volumen de El Capital (MARX, 2014a).

Marx (2014a) propuso que existió una acumulación previa a la acumulación capitalista, que fue uno de los factores que permitió dar origen a este sistema. De ahí deriva el nombre de acumulación originaria o acumulación primitiva, ya que no es resultado del modo de producción capitalista, sino más bien su punto de partida, lo que permite que se establezca este modo de producción y las relaciones sociales consecuentes. Las relaciones de producción bajo el capitalismo suponen una separación entre capital y trabajo. Una vez establecida la producción capitalista, la misma no sólo mantiene esa división sino que la profundiza y la reproduce en escala cada vez mayor. La llamada acumulación originaria no es, por consiguiente, más que el proceso histórico de escisión entre productor y medios de producción. Aparece como originaria porque configura la prehistoria del capital y del modo de producción correspondiente al mismo.

El proceso de acumulación por desposesión corresponde a una etapa de desarrollo o madurez del sistema capitalista, donde una vez establecido el mismo, existe la necesidad por parte de los capitalistas de avanzar con distintos modos de expropiación sucesivos para poder reproducir las formas de explotación características y garantizar la tasa de ganancia de los capitalistas, que a lo largo de la historia presenta una tendencia decreciente (MARX, 2014b) ${ }^{2}$. Harvey $(2004,2007)$ define este proceso de acumulación por desposesión como una continuación y proliferación de las prácticas descritas por Marx como originarias o primitivas al comienzo del capitalismo, que incluyen la privatización de la tierra; la expulsión forzosa de poblaciones campesinas; la conversión de diversas formas de derechos de propiedad (común y colectiva) en derechos de propiedad privada exclusivos; supresión de derechos a los bienes comunes; mercantilización de la fuerza de trabajo y la supresión de formas alternativas (indígenas) de producción y consumo; procesos de apropiación de activos como los biene naturales; monetización de cambio e impuestos, particularmente de tierras; el tráfico de personas; la usura, la deuda nacional y, el uso del sistema de crédito como medio radical de acumulación primitiva. El autor resalta que el estado, con su monopolio de la violencia y las definiciones de legalidad, juega un papel crucial en estos procesos (HARVEY, 2007).

Este marco conceptual es relevante para analizar el devenir histórico y la actualidad de los pueblos aborígenes en el noreste argentino (y en el resto de Nuestra América) desde un fundamento económico-político general.

\section{El confinamiento de los pueblos}

La historia de los pueblos indígenas enmarcada en el desarrollo capitalista argentino introducido brevemente, es una historia signada por la explotación social, la represión y la persecución. Desde la llegada de los conquistadores españoles, donde los indígenas ocupaban lo que conforma parte del actual territorio de Argentina, Paraguay y Brasil, hasta el siglo XX, los pueblos aborígenes fueron siendo perseguidos, exterminados y recluidos. En particular, el poblamiento

\footnotetext{
${ }^{2}$ La tendencia decreciente de la tasa de ganancia capitalista es una idea presentada por Karl Marx, por la cual el aumento de la composición orgánica del capital conduce a una menor tasa de extracción del plusvalor por parte de los capitalistas.
} 
del territorio nacional argentino, durante mediados de siglo XIX a principios del siglo XX, implicó una política decidida de genocidio de los pueblos aborígenes por parte del estado argentino. Como señala Sarasola (2013), esta política se vio enfrentada por numerosas rebeliones indígenas que terminaron finalmente en masacres, y concluyeron con los pueblos indígenas recluidos en zonas específicas como una suerte de coto. La masacre de Napalpí es el punto cúlmine de estos procesos de rebelión contra el estado argentino y su aparato represor.

En el caso de Argentina, la acumulación por desposesión de las empresas capitalistas estuvo a cargo del estado nacional. Luego de la Guerra del Paraguay comenzó el desarrollo capitalista en la zona del Noreste argentino, bajo la presidencia de Sarmiento. Las zonas del Gran Chaco fueron ocupadas por el ejército argentino durante el transcurso de esta guerra infame, lo que implicó el uso de una violencia intensa, masiva y sistemática contra la población nativa, que fue reducida en campañas militares, que impuso el terror a efectos de controlar el territorio. El siguiente paso fue la proletarización forzosa de los indígenas, en obrajes, tabacaleras, cultivos o ingenios, que se llevó delante de forma sistemática. La creación de una clase obrera explotada en condiciones inhumanas, para asegurar el progreso capitalista, requirió la militarización masiva del territorio chaqueño. Esta proletarización forzada siguió el objetivo de desarrollo de la industria taninera, el cultivo de algodón y la demanda de durmientes para el ferrocarril.

En este sentido, los pueblos originarios fueron reprimidos, aislados y asimilados como trabajadores asalariados al sistema capitalista en desarrollo en nuestro país. Allí donde los pueblos fueron confinados, es donde la lengua vernácula toma una relevancia máxima. Una educación en lengua oficial castellana, desde un enfoque de la cultura oficial, no sólo es un obstáculo de aprendizaje sino que se constituye en un acto de violencia contra un pueblo oprimido, perseguido y doblemente explotado por su condición de trabajadores asalariados e indígenas.

\section{Fundamentos desde la enseñanza de las ciencias naturales}

La enseñanza de las Ciencias Naturales sufrió numerosas transformaciones en las últimas décadas, con el objetivo de lograr mejores aprendizajes, una mayor motivación intrínseca por parte de los estudiantes y a promover una mejor visión acerca de la ciencia, lo que permitiría desarrollar vocaciones científicas en los jóvenes (COUSO, 2013; IZQUIERDO, 2017). Si bien existe una tendencia cada vez mayor a la contextualización de los contenidos científicos escolares, en general, las reformas de diseños curriculares, de materiales didácticos y de enfoques utilizados en la escuela secundaria, incorporan solo algunos aspectos de las culturas de las poblaciones de destino, colocando el énfasis en el diseño de estrategias para que los estudiantes desarrollen competencias científicas y el aprendizaje de contenidos disciplinares clave. Estas competencias científicas e ideas clave de la ciencia cobran sentido cuando están conectadas con fenómenos de la naturaleza y con la posibilidad de intervenir directamente en el entorno, es decir, cuando están contextualizadas (COUSO, 2013; IZQUIERDO, 2017).

Por lo tanto, si las actividades escolares se basan en la repetición de los modelos o teorías de científicas de la ciencia erudita, sin una transposición didáctica y contextualización adecuada implicarán una actividad vacía o la cáscara de una 
actividad que estará hueca. Es decir, es necesario generar actividades de ciencia escolar que impliquen problemas reales para los estudiantes, en escenarios contextualizados para que la ciencia escolar tenga sentido para los estudiantes (CHAMIZO; IZQUIERDO, 2005). Por otra parte, Candau (2008) discute la relevancia de implementar un discurso desde los derechos humanos en contextos de Educación Intercultural, señalando que uno de los principales desafíos es la deconstrucción de preconceptos y discriminación que se invisivilizan de forma sutil en las relaciones escolares de poder monocultural y etnocéntricas actualmente vigentes.

Por otro lado, las investigaciones realizadas en el campo de la Didáctica de las Ciencias Naturales, en particular, han indagado y relevado durante más de 30 años las concepciones y representaciones mentales de los estudiantes en los procesos de enseñanza y de - aprendizaje de contenidos científicos, lo cual llevó a concluir que es indispensable considerar estas concepciones para generar actividades escolares. Este concepto teórico fundamental de la didáctica de las ciencias, invierte el paradigma educativo que hasta comienzos de los 1980 se basaba en la transmisión adecuada de información científicamente correcta por parte de los docentes, a uno centrado en los estudiantes, donde relevar sus concepciones se volvió una tarea clave durante las actividades educativas. La enseñanza dejó de estar orientada a un estudiante con un rol completamente pasivo donde podía estar o no estar, pensar o no pensar, tener ciertos rasgos culturales u otro, a jugar un rol activo y central. Bajo este paradigma no se podría pensar el diseño de actividades estandarizadas y descontextualizadas que no contemplaran las particularidades de las poblaciones estudiantiles, más aún si se trata de una población cultural específica como la de los pueblos aborígenes (CHADWICK, 2019; CHADWICK: BONAN, 2018).

\section{Los contenidos a enseñar como contenidos escolares específicos}

En consonancia con lo planteado en las secciones anteriores, el diseño de actividades escolares que permitan a los estudiantes identificar problemas de su entorno, que puedan ser explicados operando con modelos científicos, a partir de los cuales se pueda plantear además una intervención activa en los mismos, requiere inevitablemente considerar específicamente a la población destinataria de esas actividades escolares. En este caso, cobra nuevamente importancia, la consideración de la ciencia como praxis, pues el objetivo de las actividades de enseñanza no será el aprendizaje de los contenidos canónicos de los modelos científicos eruditos por parte de los estudiantes, sino construir representaciones mentales o esquemas de acción que les permitan intervenir en su medio tanto para explicarlos como para transformarlo. Los modelos científicos que se enseñan en la escuela deben permitir a los estudiantes identificar problemas del mundo real e intervenir en el mismo. Según Chamizo e Izquierdo (2005), los estudiantes tienen que ser capaces de identificar las problemáticas de su entorno de manera tal de que puedan explicarlos simbólicamente y darles sentido en base a los conceptos que deben de aprender a través de los programas disciplinares escolares. Es importante aclarar que la postura anteriormente descripta, es solo una de las perspectivas actuales ya que fue discutida por autores como Cobern y Loving (2001) desde la mirada de los pluralistas epistemológicos, como así también desde la observación de la educación culturalmente 
sensible sostenida por El-Hani y Sepúlveda (2006), Venegas y Molina (2014) con conglomerado de relevancias, y Aikenhead $(1996,1997,2001)$ con traspaso de fronteras.

Las características de las actividades que llevamos a cabo en este sentido, son específicas y deben considerar necesariamente al estudiante como un participante activo en las mismas. Este es uno de los aspectos por los cuales se pueden considerar como actividades y formas de construcción del conocimiento específicas del contexto escolar, considerándolas como actividades de ciencia escolar. Considerando el modelo de transposición didáctica (CHEVALLARD, 1997), se puede fundamentar esta relación bidireccional entre la ciencia erudita y la ciencia escolar, donde esta última, a pesar de compartir rasgos con su análoga erudita, tienen numerosas características propias distintas y se constituye en una entidad autónoma. Los saberes científicos que se pretenden enseñar sufren transformaciones para ser convertidos en objetos de enseñanza. Tanto los docentes, como participantes activos de esta transformación de los saberes, como los estudiantes, participantes activos en el trabajo con los objetos de enseñanza, son relevantes y determinantes a la hora de operar esta transposición didáctica. Por lo tanto, no resulta la misma transposición, inclusive de un mismo conjunto de saberes científicos, para poblaciones de estudiantes distintas; el docente, como profesional de la enseñanza operará distintas transformaciones o apelará a materiales distintos dependiendo de los estudiantes a los cuales se dirija y de sus particularidades.

Como se puede apreciar, en base a estos fundamentos y tal como afirma Walsh (2010), es de suma necesidad generar estrategias didácticas desde las nuevas perspectivas críticas para obtener una educación científica de calidad para las poblaciones estudiantiles multiculturales y multilingües de nuestro país, Argentina y de Nuestra América.

\section{Algunas reflexiones acerca de los materiales didácticos para poblaciones culturalmente diversas en clases de ciencias}

El desarrollo de materiales de enseñanza de las Ciencias Naturales es indispensable para transformar los saberes eruditos en contenidos científicos escolares enseñables. Es evidente que estos materiales escolares, si bien deben ser generales para socializar y homogeneizar los contenidos destinados a un conjunto de la población, deben atender las particularidades de poblaciones específicas como son los pueblos aborígenes. Es decir, deben ser materiales diseñados cuidadosamente contextualizados.

Como relevan numerosas investigaciones tales como Chadwick (2019), Hirsch y Serrudo (2010a), Nucinkis (2006), entre otros, que hacen alusión a la implementación de enfoques EIB en distintos lugares de Nuestra América, el desarrollo de materiales didácticos específicos que aborden la cultura aborigen destinataria, su lenguaje, sus tradiciones, sus modelos explicativos, etc. es determinante para que estas iniciativas sean provechosas. En particular, el idioma en poblaciones bilingües o multilingües es un aspecto fundamental para tener en cuenta al abordar estas propuestas. Tal como firman Hirsch y Serrudo (2010a), una implementación que no tuviera en cuenta las tensiones relacionadas con el idioma, podría recaer en un enfoque castellanizador. 
Por otro lado, contar con materiales didácticos específicos desde el enfoque EIB permite romper con una mirada etnocéntrica y asimiladora que caracterizó a los intentos desde el estado para escolarizar a las poblaciones de jóvenes aborígenes (HIRSCH; SERRUDO, 2010b; HIDALGO HERNÁNDEZ, 2005). Esto implica no sólo incorporar la mirada plurilingüe, sino también abordar en los materiales educativos los contextos de vida de los pueblos aborígenes, los modelos explicativos propios de su cultura que se transmiten tradicionalmente y que les permiten operar sobre su entorno cotidianamente.

Es importante destacar que nosotros creemos que una enseñanza de las ciencias intercultural de calidad está dada por la búsqueda de puentes o vínculos entre los conocimientos de la ciencia a enseñar y los saberes vernáculos desde un lugar de valoración (CHADWICK, 2019; CHADWICK; BONAN, 2018) de manera tal de visibilizar y poner de manifiesto en la escena escolar las relaciones de poder de un legado colonial y el etnocentrismo de la ciencia occidental aún vigentes en el territorio de Nuestra América.

\section{La confección de materiales específicos para la ElB: una cuenta pendiente}

Como dan cuenta investigaciones (CHADWICK; BONAN, 2018; HIRSCH; SERRUDO, 2010b) que realizan un balance sobre la EIB en Argentina, la confección de materiales propios para la implementación de la misma sigue siendo una cuenta pendiente por distintas razones. Algunos países de Nuestra América que han implementado enfoques EIB han confeccionado materiales propios como es el caso de Bolivia, donde los módulos diseñados contemplaban la lengua indígena como la principal para la confección de materiales específicos y el español como segunda lengua (NUCINKIS, 2006). Así mismo, en el caso de Bolivia se detecta como un reto urgente para el futuro la necesidad de mejorar estos materiales tanto por su estructuración y diseño como por la necesidad de abarcar áreas y niveles que aún no fueron contemplados.

En el caso de Ecuador, se cuenta con una larga tradición de materiales didácticos específicos, pero la limitación es que la mayoría se han centrado en la lengua quichua. En este sentido, el reto es generar materiales educativos que abarquen las distintas lenguas y niveles presentes en el territorio (GARCÉS, 2006).

Por otra parte, en Argentina existen materiales didácticos en su mayoría relacionados con la lingüística sin embargo, el área de Ciencias Naturales es un área de vacancia. Entre los materiales didácticos publicados relacionados con las Ciencias Naturales podemos destacar el libro de libre descarga: Propuestas didácticas para la formación docente multicultural (BONAN, 2017b) el cual ronda en torno a la temática del cielo en la cosmovisión Qom. Por otra parte, el contexto actual de la pandemia de COVID-19 llevó a la virtualización de la educación promoviendo la construcción de plataformas digitales de libre acceso a nivel provincial. En particular, la provincia de Chaco elaboró la Plataforma ELE, la cual cuenta con propuestas didácticas para diferentes niveles educativos y etnias tales como la Qom, Mocoit y Wichí en contextos de EIB. Esta plataforma cuenta con propuestas de enseñanza elaboradas por Profesores Bilingües según su etnia de pertenencia como así también por docentes criollos y atraviesan diferentes áreas curriculares. Si bien el número de propuestas es acotado, la Plataforma ELE logró visibilizar algunos de los trabajos y metodologías indígenas de enseñanza. 
Estos casos son sólo algunos ejemplos, que deben ir acompañados de campañas de formación docente y pensamiento crítico, más aún en el contexto actual de virtualización impuesta de la enseñanza que se experimenta a nivel mundial a causas de la pandemia de COVID-19. Un aspecto que si bien no se ha abordado en profundidad en el presente trabajo pero no se puede pasar por alto.

\section{Conclusiones}

Actualmente algunos de los objetivos transversales que tiene la educación institucional son generar ciudadanos que puedan intervenir y operar en el mundo, y lograr socializar los conocimientos para que sean abordables por el conjunto de la población. En un marco social donde la información es inabordable desde el punto de vista individual, el acceso al conocimiento socialmente legitimado, es una necesidad imprescindible, pues es lo que permite a los estudiantes como futuros ciudadanos actuar críticamente sobre la información a la que acceden.

La implementación de enfoques educativos que contemplen la diversidad cultural al interior de las aulas de Ciencias Naturales en particular es indispensable para los países de Nuestra América. Esto se debe en parte a que reconocer nuestras características propias y ser conscientes de nuestra identidad heterogénea de forma tal de construir una comunidad nueva siendo consolidada a través de una fisonomía propia y no como algo trasplantado de Europa (CHADWICK, 2019). Según esta autora, en este escenario la interculturalidad se orienta a la construcción epistémica de una nueva condición social del saber, concebida como parte de un proyecto político en respuesta a los legados coloniales aún presentes.

Es por eso que es necesario incorporar dentro del cuerpo de conocimiento legitimado por la sociedad y por las escuelas en general, aquellos conocimientos de los pueblos aborígenes en especial, dándose mediante un marco institucional. Siendo las propuestas interculturales de enseñanza para todos los estudiantes y no solo para aquellos que pertenezcan a las etnias aborígenes.

En este sentido, en este trabajo de reflexión se defiende contemplar el enfoque de enseñanza intercultural desde tres fundamentos metacientíficos que están ligados o inclusive se intersecan para justificar la necesidad de la implementación de una educación con estas características para fomentar una verdadera política democrática e igualitaria en términos de educación científica.

\section{Referencias}

ADÚRIZ-BRAVO, A.; IZQUIERDO, M. Acerca de la didáctica de las ciencias como disciplina autónoma. Revista Electrónica de Enseñanza de las Ciencias, Vigo, v. 1, n. 3, p. 130-140, 2002. Recuperado el 16 jul. 2021 de: https://cutt.ly/AmL3oq2.

AIKENHEAD, G. Integrating western and aboriginal sciences: cross-cultural science teaching. Research in Science Education, Dordrecht, v. 31, n. 3, p. 337-355, 2001. DOI: https://doi.org/cnzjbr.

AIKENHEAD, G. Science education: border crossing into the subculture of science. Studies in Science Education, Abingdon, v. 27, n. 1, p. 1-52, 1996. DOI: https://doi.org/d7t9s5.

AIKENHEAD, G. Toward a first nations cross cultural science and technology curriculum. Science \& Education, Dordrecht, v. 81, n. 2, p. 217-238, 1997. Recuperado el 13 Jul. 2021 de: https://cutt.ly/tmSYYSE. 
ARGENTINA. Instituto Nacional de Estadística y Censos. Censo nacional de población, hogares y viviendas 2010: censo del bicentenario: resultados definitivos. Buenos Aires: INDEC, 2012. v. 1.

BOLIVIA. Ley $n^{\circ}$ 070. Ley de 20 de diciembre de 2010. Ley de la educación "Avelino SiñaniElizardo Pérez". [La Paz]: Asamblea Legislativa, 2010. Recuperado el 13 Jul. 2021 de: https://cutt.ly/UmSQVXr.

BONAN, L. La formación docente y la creación de materiales didácticos para la educación científica intercultural. In: QUINTANILLA GATICA, M. (comp.). Multiculturalidad y diversidad en la enseñanza de las ciencias: hacia una educación inclusiva y liberadora. Santiago de Chile: Bellaterra, 2017a. p. 50-70.

BONAN, L. (comp.). Propuestas didácticas para la formación docente multicultural. Don Torcuato: Geraldine Chadwick, 2017b. Recuperado el 16 jul. 2021 de: https://cutt.ly/1 mL8wbk.

CANDAU, V. Direitos humanos, educação e interculturalidade: as tensões entre igualdade e diferença. Revista Brasileira de Educação, Rio de Janeiro, v. 13, n. 37, p. 45-56, 2008.

CARRERA, N. I. Campañas militares y clase obrera Chaco, 1870-1930. Buenos Aires: Centro Editor de América Latina, 1984.

CARRERA, N. I. La violencia como potencia económica: Chaco, 1870-1940: el papel del estado en un proceso de creación de condiciones para la constitución de un sistema productivo rural. Buenos Aires: Centro Editor de América Latina, 1988.

CENSABELLA, M. Las lenguas indígenas de la Argentina: una mirada actual. Buenos Aires: Eudeba, 2005.

CHADWICK, G. Aporte a la educación intercultural bilingüe: los vínculos entre las representaciones científicas y vernáculas sobre Las Pléyades en el Gran Chaco. 2019. Disertación (Maestría en Educación) - Facultad de Filosofía y Letras, Universidad de Buenos Aires, Buenos Aires, 2019.

CHADWICK, G.; BONAN, L. Educación científica intercultural: tendiendo puentes conceptuales sobre las Pléyades en el Gran Chaco. TED: tecné, episteme y didaxis, Bogotá, n. 43, p. 17-29, 2018. DOI: https://doi.org/10.17227/ted.num43-8649.

CHAMIZO, J. A.; IZQUIERDO, M. Ciencia en contexto: una reflexión desde la filosofía. Alambique, Barcelona, n. 46, p. 9-17, 2005. Recuperado el 16 jul. 2021 de: https://cutt.ly/smL89qZ.

CHEVALLARD, Y. La transposición didáctica: del saber sabio al saber enseñado. 2. ed. Buenos Aires: Aique, 1997.

COBERN, W.; LOVING, C. Defining "science" in a multicultural world: implications for science education. Science Education, Hoboken, v. 85, n. 1, p. 50-67, 2001. Recuperado el 13 Jul. 2021 de: https://cutt.ly/ImSPFQk.

CORTINA, R.; EARL, K. Advancing professional development for teachers in intercultural education. Education Sciences, Basel, v. 10, n. 360, p. 1-12, 2020. DOI: https://doi.org/gqb5.

COUSO, D. La elaboración de unidades didácticas competenciales. Alambique: didáctica de las ciencias experimentales, Barcelona, n. 74, p. 12-24, 2013.

CULLEN, C. Reflexiones desde nuestra América. Buenos Aires: Las Cuarenta, 2016.

ECHEVERRÍA, J. Filosofía de la ciencia. 2. ed. Madrid: Akal, 1998.

EL-HANI, C. N.; MORTIMER, E. F. Multicultural education, pragmatism, and the goals of science teaching. Cultural Studies of Science Education, Dordrecht, v. 2, p. 657-702, 2007. DOI: https://doi.org/bdqw68. 
EL-HANI, C. N.; SEPÚLVEDA, C. Referenciais teóricos y subsídios metodológicos para a pesquisa sobre as relações entre educação científica e cultura. In: SANTOS, F. M. T.; GRECA, I. M. Pesquisa em ensino de ciências no Brasil e suas metodologias. ljuí: Ed. Unijuí, 2006. p. 161-212.

GARCÉS, F. La EIB en Ecuador. In: LÓPEZ, L., E.; ROJAS, C. (ed.). La EIB en América Latina bajo examen. La Paz: Plural, 2006. p. 111-183.

GROSFOGUEL, R. La descolonización de la economía política y los estudios postcoloniales: transmodernidad, pensamiento fronterizo y colonialidad global. Tabula Rasa, Bogotá, n. 4, p. 1746, 2006. DOI: https://doi.org/10.25058/20112742.245.

HARDING, S. Is science multicultural?: postcolonialisms, feminisms, and epistemologies (race, gender, and science). Bloomintong: Indiana University Press, 1994.

HARVEY, D. Neoliberalism as creative destruction. Annals of the American Academy of Political and Social Science, Philadelphia, n. 610, p. 22-44, 2007.

HARVEY, D. El nuevo imperialismo. Madrid: Akal, 2004.

HIDALGO HERNÁNDEZ, V. Cultura, multiculturalidad, interculturalidad y transculturalidad: evolución de un término. Universitas Tarraconensis: ciències de l'educació, Tarragona, n. 1, p. 7585, 2005.

HIRSCH, S.; SERRUDO, A. La educación en comunidades indígenas de la argentina: de la integración a la educación intercultural bilingüe. In: HIRSCH, S.; SERRUDO, A. (comp.). La educación intercultural bilingüe en Argentina: identidades, lenguas y protagonistas. Buenos Aires: Novedades Educativas, 2010a. p. 17-44.

HIRSCH, S.; SERRUDO, A. (comp.). La educación intercultural bilingüe en Argentina: identidades, lenguas y protagonistas. Buenos Aires: Novedades Educativas, $2010 \mathrm{~b}$.

HORSTHEMKE, K.; YORE, L. D. Challenges of multiculturalism in science education: indigenisation, internationalisation, and transkulturalität. In: MATTHEWS, M. (ed.). International handbook of research in history, philosophy and science teaching. Dordrecht: Springer. 2014. p. 1759-1792.

IVIC, I. Lev S. Vygotsky (1896-1934). Perspectivas: revista trimestral de educación comparada, Paris, v. 24, n. 3-4, p. 773-799, 1994.

IZQUIERDO, M. Atando cabos entre contexto, competencias y modelización: ¿es posible enseñar ciencias a todas las personas? Modelling in Science Education and Learning, Valencia, v. 10, n. 1, p. 309-326, 2017. DOI: https://doi.org/10.4995/msel.2017.6637.

LAM, L.; FRISANCHO, S.; VILLALBA, J. Conocimiento físico sobre un dispositivo mecánico del pueblo asháninka: el caso de una trampa para cazar. Schème, Marília, v. 12, n. 1, p. 6-40, 2020. Recuperado el 12 jul. de: https://revistas.marilia.unesp.br/index.php/scheme/article/view/10745.

LÓPEZ, L. E.; ROJAS, C. (ed.). La ElB en América Latina bajo examen. La Paz: Plural, 2006.

MARTÍ, J. Nuestra América. In: MARTÍ, J. Nuestra América. Caracas: Biblioteca Ayacucho, 1977. p. 26-33.

MARX, K. El capital: crítica de la economía política, tomo I, libro I: el proceso de producción del capital. 4. ed. México: Fondo de Cultura Económica, 2014a.

MARX, K. El capital: crítica de la economía política, Libro III: el proceso de conjunto de la producción capitalista. 4. ed. México: Fondo de Cultura Económica, 2014b.

MESSINEO, C.; CÚNEO, P. Las lenguas indígenas de la argentina: situación actual e investigaciones. In: WELER, A.; REYNA MUNIAIN, F.; TOREM, G. (ed.). Lenguas de Europa y América. Buenos Aires: Fundación Xeite Nova de Cultura Gallega, 1998. p. 37-74. 
MOLINA, A.; MOJICA, L. Enseñanza como puente entre conocimientos científicos escolares y conocimientos ecológicos tradicionales. Magis, Bogotá, v. 6, n. 12, p. 37-53, 2013.

MOLINA, A.; MARTINEZ, C.; MOSQUERA, C.; MOJICA, L. Diversidad cultural e implicaciones en la enseñanza de las ciencias: reflexiones y avances. Revista Colombiana de Educación, Bogotá, n. 56, p. 106-130, 2009.

NOVARO, G. Interculturalidad y educación: reflexiones desde las experiencias formativas de niños indígenas y migrantes. In: NOVARO, G. (comp.). La interculturalidad en debate: experiencias formativas y procesos de identificación en niños indígenas y migrantes. Buenos Aires: Biblos, 2011. p. 15-33.

NUCINKIS, N. La EIB en bolivia. In: LÓPEZ, L. E.; ROJAS, C. (ed.). La EIB en América Latina bajo examen. La Paz: Plural, 2006. p. 25-100.

OLIVARES, M.; PENA, C. Teaching health sciences students about culturally sensitive communication between health professionals and patients from diverse cultures. International Journal of Bilingual Education and Bilingualism, England, v. 18, n. 1, p. 113-126, 2015.

PERKINS, D. El aprendizaje pleno. Buenos Aires: Paidós. 2016.

RAJ, K. Relocating modern science: circulation and construction of knowledge in South Asia and Europe. Houndmills: Palgrave Macmillian, 2007.

SARASOLA, C. Nuestros paisanos los indios. Buenos Aires: Del Nuevo Extremo, 2013.

SEOANE, J.; TADDEI, E.; ALGRANATI, C. Recolonización, bienes comunes y alternativas desde los pueblos: diálogo de los pueblos. Rio de Janeiro: IBASE, 2010.

TANNER, P. E. Teacher educators and indigenous language rights reform in Southern Mexico. 2012. 245 p. Dissertation (Doctor of Philosophy) - Michigan State University, East Lansing, 2012. Recuperado el 13 Jul. 2021 de: https://cutt.ly/tmSAx0l.

THISTED, S. Culturas magisteriales y educación intercultural en Argentina: construcción histórica de posiciones docentes ante las diferencias y las desigualdades. In: SEMINARIO INTERNACIONAL DE LA RED ESTRADO, 11., 2016, México. Actas [...]. Recuperado el 20 mar. 2020 de: https://cutt.ly/9QdCJag.

VENEGAS, A.; MOLINA, A. Conglomerado de relevancias en el discurso de un niño llanero sobre la naturaleza. TED: tecné, episteme y didaxis, Bogotá, n. extra, p. 302-309, 2014. DOI: https://doi.org/10.17227/01203916.3220.

VOSNIADOU, S.; IOANNIDES, C.; DIMITRAKOPOULOU, A.; PAPADEMETRIOU, E. Designing learning environments to promote conceptual change in science. Learning and Instruction, England, v. 11, n. 4-5, p. 381-419, 2001.

VYGOTSKY, L. Internalización de las funciones psicológicas superiores. In: VYGOTSKY, L. EI desarrollo de los procesos psicológicos superiores. Barcelona: Ed. Crítica, 1978. p. 87-94.

WALSH, C. Interculturalidad, conocimientos y decolonialidad: perspectivas y convergencias. Signo y Pensamiento, Bogotá, v. 24, n. 46, p. 39-50, 2005.

WALSH, C. Interculturalidad crítica y educación intercultural. In: VIAÑA UZIEDA, J.; TAPIA MELLA, L.; WALSH, C. E. Construyendo interculturalidad crítica. La Paz: Convenio Andrés Bello: Instituto Interamericano de Integración, c2010, p. 75-96. 